\title{
ACESSO À JUSTIÇA APARENTE - A JUDICIALIZAÇÃO DE CONFLITOS SOB UMA PERSPECTIVA MAIS PRAGMÁTICA
}

\author{
Tatiana Bettiol Carneiro ${ }^{1}$ \\ Luiz Henrique Urquhart Cademartori²
}

\begin{abstract}
Resumo: A definição do acesso à justiça passou por mutações, abrangendo novas formas de resolução de conflitos e significando além da possibilidade de judicialização de demandas, a procedibilidade célere e com a observância de garantias constitucionais. Entretanto, a capacidade institucional do Poder Judiciário brasileiro impede a garantia desse acesso como almejado pela sociedade. Esse artigo pretende analisar, por meio do método dedutivo, o acesso à justiça ilimitado, ponderando questões como a análise econômica da litigância, tragédias dos comuns, teoria dos jogos e a eficiência do Poder Judicante.
\end{abstract}

Palavras-Chave: Acesso à Justiça; Análise econômica da litigância; Teoria dos Jogos; Tragédia dos Comuns; Eficiência

\section{ACCESS TO APPEAL JUSTICE - JUDICIALIZATION OF CONFLICTS WITH A MORE PRAGMATIC PERSPECTIVE}

\begin{abstract}
The definition of access to justice has undergone mutations, encompassing new forms of conflict resolution and signifying beyond the possibility of judicialisation of demands, speedy procedurality and compliance with constitutional guarantees. However, the institutional capacity of the Brazilian Judiciary prevents the fulfillment of its role as intended by society. This article aims to analyze access to unlimited justice, through issues such as economic analysis of litigation, tragedies of commons, theory of games and the efficiency of the Judiciary.
\end{abstract}

Keywords: Access to justice; Economic Analysis of Litigation; Theory of Games; Tragedy of Commons; Efficiency

\section{INTRODUÇÃO}

O acesso à justiça do Projeto de Florença promoveu uma maximização da procura da prestação jurisdicional para resolução de conflitos e teve importância fundamental na propagação e reconhecimento dos direitos decorrentes do devido processo legal. 
Todavia, a ampliação da postulação de direitos por meio de judicialização, aliado a outras variáveis, sobrecarregou a capacidade institucional do Poder Judiciário, tornando menos satisfatória a prestação jurisdicional.

O acesso à Justiça ilimitado, com o número de demandas crescentes em progressões geométricas, é possível de concretização na plenitude e abrangência de sua definição, em um Poder Judiciário abarrotado, que possui limitações orçamentárias e estruturais?

A justificativa da pesquisa decorre da disparidade entre o crescente aumento de demandas e da capacidade de absorção pelo Poder Judiciário. A propagação do amplo e acesso ilimitado ao Poder Judicante é discrepante da sua realidade atual, resultando em um sistema ineficiente e no acesso à justiça apenas aparente. É necessário que ponderações sobre aspectos ligados à litigância sejam realizados para que se possa estabelecer mecanismos de freios e contrapesos.

O objetivo é analisar a possibilidade de aplicação do acesso à justiça por meio de judicialização em seu significado atual, que engloba além da postulação, o direito garantido com celeridade e adequadamente, no atual Sistema Judicante, explanando sobre alguns pontos estratégicos que podem ser fundamentais para essa concretização.

O método a ser utilizado será o dedutivo, posto que a investigação acerca do tema inicialmente está calcada em um estudo geral sobre o acesso à justiça em sua concepção atual, analisando questões pertinentes como análise econômica da litigância, tragédia dos comuns, teoria dos jogos e eficiência, até chegar-se ao enfoque particular, o qual trata da adequação do acesso à justiça de forma pragmática às possibilidades do Poder Judiciário.

Cumpre ressaltar, que a presente pesquisa não visa esgotar todas as possibilidades que enredam o tema sugerido ou fazer uma análise histórica, mas tenta esboçar, de forma concisa, os aspectos que o envolvem, buscando solucionar a problemática proposta de forma razoável e em consonância com a ordem jurídica.

A sociedade contemporânea precisa repensar o acesso à justiça sob enfoque mais pragmático, ponderando questões como análise econômica da litigância, tragédia dos comuns, aplicação da teoria dos jogos e eficiência do Poder Judiciário, propondo uma desconstituição de valores consolidados.

A preocupação crescente com a efetividade e eficiência da prestação jurisdicional deve ser propulsora para que se repense os postulados do acesso à justiça, visando a adequação necessária para que possa garantir a sua autenticidade. 


\section{BREVE CONCEITUAÇÃO DE ACESSO À JUSTIÇA}

O acesso à Justiça é a garantia de postulação de direitos, seja por meio da judicialização ou por outra forma adequada de resolução de conflito, abrangendo desde a postulação, a instrumentos apropriados e céleres, respeitando as garantias constitucionais em sua procedibilidade.

A definição de acesso à justiça como possibilidade de resolução de conflito está descrita no Manual de Mediação Judicial do Conselho Nacional de Justiça (2015, p. 39) da seguinte forma:

\footnotetext{
Nota-se assim que o acesso à justiça está mais ligado à satisfação do usuário (ou jurisdicionado) com o resultado final do processo de resolução de conflito do que com o mero acesso ao poder judiciário, a uma relação jurídica processual ou ao ordenamento jurídico material aplicado ao caso concreto.
}

Atendo-se que a conceituação moderna desse instituo abrange fases de postulação e procedibilidade, o direito ao acesso à justiça garante acesso à justiça adequadamente organizada e por instrumentos aptos e efetivos. (RODRIGUES, 2016, p. 104).

Trata-se de direito amplo, não se limitando ao acesso ao Poder Judiciário, mas à ordem jurídica justa, com todas as garantias contempladas para tanto.

\section{ANÁLISE ECONÔMICA DA LITIGÂNCIA}

A proposição de lides pode ser analisada sob várias vertentes, seja na sua motivação, nas regras acerca do seu procedimento, seja nas suas consequências, ou ainda, na questão econômica que a envolve.

Richard Posner (2007) é um autor que propõe uma reflexão sobre o impacto das questões de capitalização que envolvem os conflitos judicializados, demonstrando que esse fator tem grande influência nos aspectos antecedentes, concomitantes e posteriores à litigância.

A proposta desse viés do processo é a análise e mensuração do valor de uma lide, ponderando os custos dos erros e quantificando as possibilidades de sucesso da demanda.

A litigância é analisada sob o aspecto de estatística e probabilidade e o resultado inclui as informações que cada uma das partes possui, mas, também, os possíveis acontecimentos no desenvolvimento do processo, o valor da possibilidade de êxito da demanda e as consequências econômicas para todo tipo de resultado (JUNIOR MARCELLINO, 2016, p. 162). 
A escolha pela opção da litigância é motivada, também, pela ponderação do custobenefício. As decisões por essa opção são embasadas em questões financeiras que analisam os custos e compensações de se ingressar e protelar resoluções de conflitos por meio do Poder Judiciário, utilizando-se do sistema de custas e dos atrasos e ineficiências para tanto.

Miguel Carlos Teixeira Patricio (2005, p. 14), disserta acerca da necessária avaliação sobre as consequências na escolha de decisões, sejam individuais ou coletivas, e englobando questões financeiras:

Pode afirmar-se, com razoável segurança, que a ponderação custos-benefícios é natural ao raciocínio de qualquer indivíduo, o que pode ser aferido ao nível das decisões econômicas individuais e, por uma extensão admissível, também ao nível das decisões colectivas. Embora seja facilmente observável essa ponderação, os elementos em que a mesma se baseia são por vezes pouco claros, podendo sequer ser percebidos pelos indivíduos. Logo, parece justificar-se uma análise desses mesmos elementos, podendo ainda divisar-se, genericamente condicionantes de índole endógena e exógena.

A racionalidade individual é a ponderação exercida pelo indivíduo ao pesar as eventuais consequências de sua escolha, colocando na balança, como popularmente se refere aos momentos de reflexão de escolhas, as alternativas possíveis e resolvendo no sentido de escolher a opção que lhe trará melhores benefícios frente aos demais caminhos. Assim, a racionalidade individual está presente em todos os momentos decisórios da existência humana e não poderia ser diferente no momento da opção pela litigância. (BAGGENSTOSS, 2017).

Destaca-se que para a conclusão de que as pessoas se conduzem por questões racionais para atos de sua vida, ponderando custos e benefícios utiliza-se a média, sem olvidar que nem sempre as pessoas são motivadas por comportamentos efetivamente racionais. (TIMM, 2012, p. 26)

Na prática, para que se promova a escolha para o ajuizamento de uma ação, deve-se ponderar, sob o aspecto econômico, o valor dos honorários da contratação de um advogado, as custas judiciais, valores para eventuais perícias e o possível valor a ser auferido com o sucesso da demanda, que obviamente deve ser superior a soma dos custos anteriormente mencionados.

Por conseguinte, quanto maior for a soma das custas básicas para o ajuizamento de ações, menor será a probabilidade de escolhas por essa alternativa. De forma contrária, quanto menor for o quantitativo de despesas, maior será a possibilidade de judicialização de conflitos. (TIMM, 2012, p. 393)

As informações que cada uma das partes possui são relevantes para análise econômica do processo, bem como para a concretização de uma transação, uma vez que a tendência é que 


\section{ACESSO À JUSTIÇA APARENTE - A JUDICIALIZAÇÃO DE CONFLITOS SOB UMA PERSPECTIVA MAIS PRAGMÁTICA}

a parte que possua os melhores dados, consiga alcançar seu objetivo, conforme será analisado mais minuciosamente na teoria dos jogos na sequência.

Outro aspecto a ser considerado, conforme os ensinamentos (Julio Cesar Marcellino Junior, 2016) são as ações frívolas, ações que tem baixa capacidade de obtenção de êxito e as ações habituais, que geralmente pertencem a grandes conglomerados. Em ambos os casos, valem-se, muitas vezes, da gratuidade ou do sistema de custas atual, abarrotando o sistema judicial com demandas em grandes números, tornando-se outro obstáculo para um Judiciário eficiente.

Um exemplo desse tipo de demanda é a análise do Agravo n. 729.870, que questiona a decisão que não admitiu o Recurso Extraordinário, pelo Supremo Tribunal Federal acerca do julgamento de uma ação de indenização por danos morais ajuizada em desfavor de um Supermercado por uma consumidora ter adquirido pães de queijo mofados no valor de $\mathrm{R} \$ 5,69$ e pleiteava uma reparação de $\mathrm{R} \$ 5.000,00$.

No julgamento do agravo interposto contra a inadmissibilidade de Recurso Extraordinário no caso supracitado, o Ministro Teori Zavaski, em 8 de outubro de 2013, se pronunciou no seguinte sentido:

O que a parte recorrente busca ver assegurado é, unicamente, o direito de obter, além
da devolução (já assegurada em primeira instância), do preço pago pela mercadoria
(R\$-5,69), uma reparação moral pela "grande frustração" pessoal de não ter podido
consumir imediatamente alguns pães de queijo, que estavam mofados quando foram
adquiridos. Por mais honestas e sérias que pretensões como essas se apresentem, não
se compreende como, em nosso País, não haja a solução por mecanismos
extrajudiciais, e que, depois de judicializadas, não possam ser definitivamente
resolvidas no âmbito dos juizados especiais. Só admitindo a falência desses Juizados
e dos demais juízos e tribunais estaduais e federais que compõem as instâncias
ordinárias é que se poderia admitir a submissão de causas como essas à apreciação do
Supremo, obrigando que a mais alta Corte Judiciária do Brasil sobre ela se debruce,
ainda que para afirmar que o recurso não deveria ter sido interposto. Sem nos custos
financeiros que isso representa aos cofres da Nação (milhares de vezes superiores ao
valor econômico da causa) e do gasto de tempo que impõe aos serviços judiciários, a
insistência em recorrer, em situações da espécie, revela que não basta haver leis no
País filtrando o acesso às instâncias extraordinárias.

De acordo com os dados do Conselho Nacional de Justiça, no Relatório Justiça em Números de 2017, dividindo a soma das despesas do ano de 2016 pela quantidade de processos no Tribunal de Justiça de Santa Catarina, cada processo possuiu um custo de R \$435,99 naquele ano. Ressalta-se que a Justiça Catarinense foi o $8^{\circ}$ Tribunal estadual com maiores despesas em 2016. De igual modo, ao se realizar o mesmo cálculo no Estado de Roraima, Tribunal estadual com menor quantitativo de despesas, o custo anual de um processo resultou em R\$ 1.458,63. Por findar, exemplificativamente, a Justiça Estadual de São Paulo, que teve o maior valor de 
despesas em 2016 entre as justiças estaduais, R\$10.697.604.346 e 25.943.503 processos em tramitação no mesmo ano, resultou em um custo anual de R\$ 412,35 por processo em 2016.

As ações de baixa probabilidade de êxito, de acordo com Miguel Carlos Teixeira Patricio (2005) são justificadas por baixos custos das custas judiciais, possibilidade de erros de julgamento, e, ainda, percepções divergentes dos possíveis resultados das ações.

A possibilidade de obtenção de lucro, motivador das ações frívolas, assim como a quantidade de ações habituais, nas quais os litigantes fazem a opção pela utilização do Judiciário como mecanismo de procrastinação no cumprimento dos seus contratos, são questões abordadas na análise econômica da litigância como obstáculos a eficiência do Poder Judiciário na execução de seus papel.

\section{TRAGÉDIA DOS COMUNS}

A tragédia dos comuns é elucidativa no aspecto do acesso à justiça aparente, uma vez que a escassez de recursos financeiros impede que a prestação jurisdicional seja satisfativa. Júlio César Marcellino Júnior (2016) esclarece que o volume imenso de demandas judiciais não pode ser assimilado em totalidade e em tempo razoável pelo Poder Judiciário, que possui limitações econômicas e de estrutura.

Ainda que se possa almejar um modelo ideal, no qual a todos é garantido o acesso à justiça, no seu sentido amplo e ilimitado, é necessário que se analise essa proposição de forma racional, observando às limitações orçamentárias e estruturais do Estado Brasileiro.

De forma pragmática, apesar de se desejar o contrário, o Poder Judiciário brasileiro não possui capacidade de atender a quantidade de demandas crescentes em escalas de progressões geométricas.

Esclarecendo aspectos da tragédia dos bens comuns, OST (1995, p. 147) proclama a frase que a descreve com clareza: “a liberdade dos bens comuns conduz à ruína de todos”.

Com o fim de elucidar a tragédia dos bens comuns, OST (1995, p. 147) cita o exemplo de um prado comum onde cada pastor pode criar a quantidade de animais que entender necessário. Com o passar do tempo, a regeneração do pasto começa a sofrer limitações e surgem as preocupações dos criadores, entretanto, por mais que as apreensões existam, individualmente eles continuam tendo interesse em aumentar o número de animais, uma vez que seu benefício é superior à desvantagem que suportam pela escassez do bem coletivo. 
Assim, pode-se concluir de modo genérico que a escassez faz refletir o uso racional das ferramentas, uma vez que não estão em abundância à disposição para utilização, caminhando para o uso administrável e para que se saiba como e o que fazer com os recursos disponíveis.

Refletindo sobre a necessidade de administração diante da escassez, Mackaay Ejan, (2015, p. 29) discorre:

Uma coisa se torna escassa quando não há mais quantidade suficiente para que todos os que a desejam possam obtê-la à vontade: é preciso escolher entre diferentes usos, ou, o que dá na mesma, regular o uso. Mas, na abundância que reinava antes, era perfeitamente supérfluo regular o uso. Quando a escassez se manifesta, não há como evitar a formulação de regras para de- terminar quais usos concorrentes devem ser aceitos. Isso ou a anarquia.

Atinente ao assunto central, qual seja o acesso à justiça, no aspecto supracitado se faz necessário repensar o sistema de custas atual, assim como mecanismos de obstar ou, ao menos criar formas que não incentivem a judicialização de conflitos, uma vez que o acesso à justiça amplo é apenas um acesso aparente.

A nova perspectiva do Poderes Judiciários brasileiros aborda a necessária prática de gestões, uma vez que o abarrotamento de processos tem se mostrado, atualmente, inevitável, conforme leciona Maria Elisa Macieira e Mauriti Maranhão (2010, p. 17)

Com isso torna-se possível evitar ou limitar o congestionamento de ações no Judiciário, condição que de outra forma dificilmente deixará de ocorrer, como consequência da dificuldade de enfrentar o inevitável acúmulo de processos, desprovido de ferramentas próprias.

Exemplificativamente, podemos perceber a divergência entre a procura e recursos disponíveis para atendimento das demandas no domínio privado, quando algumas lojas ofertam produtos com preços muito abaixo do mercado, recebem um aumento significativo de pedidos e não possuem ferramentas para honrar seu compromisso diante do crescimento do número de aquisições.

Os números do Relatório do Justiça em Números do Conselho Nacional de Justiça de 2017 apontam esse crescente aumento de demandas e, consequentemente, a disparidade ente a procura e as reais condições de se atender os pedidos. Não se pode olvidar que a análise econômica da litigância é uma visão pragmática e vai de encontro com a nova perspectiva da sociedade, na qual a economia possui lugar primordial.

\section{TEORIA DOS JOGOS}


A teoria dos jogos, que é um mecanismo de leitura formal, no qual a análise de custo benefício se utiliza das informações existentes, assim, dadas as regras do caso concreto como eu posso antever o comportamento do oponente. Pode ser aplicada em qualquer interação humana, pois envolve sujeitos racionais maximizadores de direitos, estabelecendo tendências de comportamento de sujeitos. A ideia é antecipar eventuais efeitos e consequências das ações, e com essas informações fazer a análise do custo/benefício.

Essa ciência analisa o comportamento racional e estratégico na interação de pessoas, definindo que as ações das pessoas estão interligadas ao comportamento das outras, havendo uma relação de interdependência (HILBRECHT, 1999, p. 115).

Assim, os jogadores, ou seja, as partes do processo, são os principais condutores da litigância e a consciência das regras e a leitura que fazem das mesmas são de suma importância e podem definir os rumos das jogadas e metas alcançadas. (ROSA, 2017, p. 50)

Referenciando-se ao acesso à Justiça e Teoria dos Jogos, os litigantes ao escolherem as jogadas, condutas no andamento do processo, utilizam as informações que possuem, tais como custas do processo, previsibilidade de sucesso de acordo, análise da jurisprudência e a quantificação dos possíveis ganhos. As questões que mobilizam seus oponentes também influenciam diretamente o litígio, como tipo de contrato advocatício firmado, pagamentos mensais ou contrato de risco por exemplo, o ajuizamento de demandas futuras diante do resultado da ação em curso, como é o caso de ações que envolvem consumidor. Sem olvidar, ainda, fatores externos como determinações do Banco Mundial, questões políticas, entre outras.

A importância da conscientização dessas questões pelos litigantes é importante seja para iniciar uma demanda, para escolha da postura adotada no curso da lide, para analisar possibilidades de acordos ou, ainda, para possíveis encerramento do litígio.

O indivíduo otimizador pondera seus interesses e realiza atitudes racionais, analisando as possibilidades e melhores estratégias a serem seguidas para a consecução do seu objetivo, em todas as atividades diárias da vivência em sociedade. Partindo da premissa do autointeresse é que se pode analisar as atitudes tomadas. (ROSA, 2017, p. 69).

A teoria dos jogos traz a lume a questão da racionalidade dos indivíduos nas escolhas de suas condutas, inclusive na opção pela judicialização dos conflitos e auxilia, ainda, a postura a ser adota pelos litigantes no decorrer do processo.

\section{GARANTIA DE EFICIÊNCIA NA ATIVIDADE JUDICANTE}


A proposta de eficiência do Poder Judiciário concentrou-se em medidas administrativas e gerenciais, buscando sanar problemas organizacionais, especialmente atinentes à questão da demora da solução das demandas judiciais.

Nessa linha, é importante destacar a divergência de efetividade e eficiência, a primeira está ligada aos fins, já a segunda aos meios. Por conseguinte, a lógica da eficiência deve ser utilizada como meio para racionalizar a prestação jurisdicional.

A eficiência está conceituada dentro da perspectiva de que a Administração Pública deve ser pautada na boa gestão, atendo-se que a eficiência do Estado deve sempre respeitar os limites legais e o interesse público, diferenciando-se da sua aplicabilidade no setor privado.

Irene Patrícia Nohara (2012, p. 217) disserta sobre os limites da razoabilidade de eficiência no setor público:

O princípio da eficiência insere-se na ótica da boa gestão. Não concordamos que o sentido da eficiência, com caráter normativo deva alcançar a noção do "ótimo", porque, conforme já tivemos oportunidade de defender, a razoabilidade deve ser o limite para o controle dos atos administrativos. Com o princípio da eficiência é, a nosso ver, um parâmetro de controle da atuação estatal, defende-se que o grau de controle jurisdicional não pode extrapolar o limite da razoabilidade.

O Judiciário não poderá, a pretexto do controle de eficiência, exigir da Administração um "agir perfeito" ou "ótimo", sem o conhecimento de inúmeros fatores que limitam a atuação administrativa no caso concreto, tais como: os recursos ao alcance ou a mão de obra disponível; sendo, repita-se, vedado determinar mais do que o razoável da Administração ou invalidar atos razoáveis sob a alegação de que eles não são "perfeitos" ou "ótimos", daí por que entendemos adequada a ideia de "boa" administração.

As atuais orientações do Conselho Nacional de Justiça são decorrentes das alterações supracitadas, em uma visão de acesso à justiça mais célere e eficaz dentro das perspectivas existentes.

O Índice de Confiança da Justiça do Brasil (ICJBrasil) na apresentação do Relatório de 2016, aponta que a ineficiência do Poder Judiciário é alvo de crítica dos brasileiros, uma vez que apenas um terço da população confia no Poder Judiciário.

De igual modo, a Ministra Carmem Lúcia ao realizar a Apresentação do Relatório do Justiça em Números do Conselho Nacional de Justiça de 2017, destacou que o comprometimento com uma prestação jurisdicional que atenda os anseios da sociedade é objetivo do Poder Judicante. 
O formato de acesso à Justiça da Escola de Florença, postula o acesso aberto e sem restrições ao sistema judicial pelos

cidadãos, está em desacordo com a ordem atual do Sistema Judiciário. Se em outro momento, as reinvindicações pretendiam garantir que todos tivessem condições de serem partes em um processo, atualmente deve-se repensar o acesso ilimitado aparente.

O Relatório da Justiça em Números do Conselho Nacional de Justiça de 2017 traz elementos acerca de dados dos processos no Judiciário Brasileiro. O Poder Judicante finalizou o ano de 2016 com 79,7 milhões de processos em tramitação, com 29,4 milhões de novos processos, ou seja, um crescimento de 5,6\% em relação a 2015. Destacou, ainda, a taxa de congestionamento, com percentual de 73\% em 2016, logo apenas $27 \%$ de todos os processos foram solucionados.

Assim, para que se possa promover o acesso à Justiça atualmente é necessário que se tenha estrutura adequada para que não se limite ao acesso ao Judiciário, mas que se tenha uma justiça que utilize os métodos mais aptos e que se possa promover a justiça propriamente dita. (RODRIGUES, 2016, p. 104).

De igual forma, outro aspecto a ser considerado é a judicialização de muitas questões, como da discricionariedade administrativa. Atinente ao tema, Luiz Henrique Urquhart Cademartori (2015, p. 179) pondera:

Diante desse quadro, típico do contexto brasileiro, entende-se que a melhor maneira de combater tal tendência é, precisamente, realçando a importância das garantias constitucionais que a constituição brasileira consagra, como diretriz primeira a orientar o controle que os operadores do direito devem efetuar sobre toda a atividade estatal.

A tendência de judicialização política também é uma das causas de entraves do acesso à justiça efetivo, direcionando muitas causas que deveriam ser tratadas em outras esferas para apreciação do Poder Judiciário.

A garantia de eficiência, como norteadora de ações, estabelece diretrizes da boa administração, que aplicados conjuntamente com normas em sentido estrito resultam em uma Administração Pública legal, efetiva e eficaz.

A Constituição da República Federativa do Brasil (1988), e a Lei do processo administrativo federal — Lei n. 9.784, de 29 de janeiro de 1999, fazem referência a necessidade de a Administração Pública pautar suas atividades sob a garantia de eficiência.

O conceito de eficiência como garantia de uma boa-gestão e não como princípio, resulta em norma abstrata, garantia à boa administração pública, na qual a condução dos atos será norteada com probidade, motivação, transparência, e outras garantias que a englobam (Juarez Freitas, 2007). 
A garantia de eficiência está relacionada à concretização da ação, utilizando racionalmente os recursos disponíveis com presteza e empregando métodos e procedimentos adequados.

Nessa esteira, a desejável boa gestão da Administração Pública, deve ser norteada pela efetividade, que pondera a análise dos fins, e a eficiência, que se relaciona aos meios, conforme suscintamente diferenciado por Julio Cesar Marcellino Junior (2016)

Exatamente por estar relacionada ao melhor aproveitamento dos meios postos à disposição para garantir o melhor resultado possível que a garantia de eficiência dentro do Poder Judiciário encontra óbices seja no elevado número de ações novas, seja no baixo índice de custas processuais que estimulam ações habituais e frívolas, questões que impedem que a limitação de recursos seja direcionada corretamente para a melhoria do sistema judicial atual.

A eficiência é pauta de todos os órgãos da Administração Pública atual, que pretendem produzir mais, de forma célere e com qualidade, entretanto por não visar lucro e possuir limitações financeiras, a eficiência na Administração Pública possui estratégias e limitações diferentes de aplicabilidade comparada ao setor privado.

Essa garantia significa o dever de escolher o meio com menos custo para a sociedade e promover de modo satisfatório os fins que são atribuídos para a Administração Pública, ou seja, a realização dos fins escolhendo os melhores meios. (MORAES, 2007, p. 215).

A autenticidade do acesso à justiça só será garantida com a conscientização da limitação de recursos existentes dentro de uma demanda crescente. O acesso à justiça propriamente dito em todos os aspectos que o envolvem, seja na garantia de propositura de ações ou na promessa de um trâmite célere, precisa que aspectos como os que foram destacados sejam refletidos e alterados.

Não se ignora que no plano ideal o acesso ao Judiciário deveria ser ilimitado, sem ônus e com qualidade e celeridade, porém não se pode esquecer que pragmaticamente esse ideal é praticamente inatingível, diante do quantitativo de novas demandas e das limitações orçamentárias.

É necessário que se tenham filtros e controles para que se garanta que o Judiciário possa proporciona, dentro de suas limitações e possibilidades, a prestação de serviço de qualidade, não se exigindo utopia dentro de questões práticas impossíveis.

A busca pela compatibilização dos novos anseios da sociedade com modelos de gestão é abordada por Daiane Sandra Tramontini (2015, p. 69): 
Nesse contexto, novas formas de gestão, pautadas na eficiência, surgem para derrubada da burocracia estatal que sempre foi tida como um grande obstáculo à nova dinâmica social, não se compatibilizando com a velocidade do mercado. A sociedade cada vez mais sedente por informação e efetividade das ações públicas, cobra forma mais veloz os resultados das políticas públicas e garantia dos direitos fundamentais.

O relatório da Justiça em Números revela o tamanho do déficit de recursos humanos por demandas, o que demonstra claramente a impossibilidade de se atender ao acesso amplo e irrestrito da Escola de Cappelletti.

Um aspecto importante a ser considerado é que não se pretende o fim de gratuidade, ao contrário, com os cuidados necessários para limitações de litigantes habituais ou de ações frívolas, o Judiciário poderá dispender seus recursos para que seja garantida a gratuidade aos que realmente necessitam. Assim como que as ações das minorias não sejam engessadas por uma estrutura que não comporta e não consegue dar vazão às suas entradas.

A reflexão de economicidade ligada a ideia de eficiência na Administração Pública é abordada por Onofre Alves Batista Júnior (2002, p. 188):

Em uma primeira aproximação, o significado de economicidade se associa à ideia
fundamental de obtenção do melhor resultado estratégico possível a partir de uma
determinada alocação de recursos econômico-financeiros, em um dado cenário
socioeconômico. Em outras palavras, traduz, sob o ponto de vista econômico-
fincanceiro, a necessidade, em cada atuação da AP, de adequação da "relação custo x
benefício", de modicidade e simplicidade da despesa, de minimização dos custos
financeiros para determinado resultado almejado, de combate ao desperdício.

A discussão é que se questione e reflita formas de que o acesso à justiça seja limitado para que se garanta que o cidadão que possui uma demanda justa não se veja dentro de uma estrutura assoberbada por questões completamente independentes de sua vontade.

O conceito de acesso à justiça é mais amplo que o simples ingresso no processo. Representa, sim, a tradução de acesso a uma justiça adequadamente organizada, com instrumentos aptos a efetividade do Direito (RODRIGUES, 2016, p. 104).

A eficiência em sentido restrito se refere à ligação entre os recursos e o resultado. A administração Pública possui recursos escassos, assim há a necessidade de se estabelecer a melhor forma de atuação para que se possa aproveitar da mais eficaz maneira possível os recursos existentes. É necessário que se faça uma otimização da relação de meios e fins, sem olvidar o fim maior qual seja o interesse público. (BATISTA JÚNIOR, 2012, p. 183).

A garantia da eficiência almejada pelo Poder Judiciário é objetivo de toda a Administração Pública, que dentro das limitações existentes, deve almejar realizar e concretizar o fim utilizando os meios disponíveis da melhor forma possível. Significa que o acesso à justiça necessita que se repense os métodos até então concebidos pelo Poder Judicante para que busque 
sua concretização com todas as garantidas de ingresso, procedimentais e de execuções possíveis.

\section{CONCLUSÃO}

A atuação do Poder Judiciário e a oportunidade de participação do cidadão dentro desse Poder passou por metamorfoses em sua concepção. Se por um momento se almejava a divulgação do livre acesso, com a propagação da informação e da popularização dessa forma de resolução de conflitos, a forma concebida atualmente almeja maior efetividade e complexidade de sua garantia.

Ao mesmo tempo que a extensão do acesso à justiça foi ampliada, passando abranger além da facilidade da postulação de causas, a garantia de procedibilidade eficaz e efetiva, entraves da propagação surgiram e a necessidade de se refletir a eficácia de seus instrumentos e métodos afloraram.

As mudanças dos anseios da sociedade refletiram também na expectativa da prestação jurisdicional, e se em outros tempos a simples entrada era sinônimo de acesso garantido, atualmente o acesso à justiça prescinde de outros elementos para sua efetividade.

A Escola de Florença que teve como um dos percussores Cappelletti teve papel fundamental na abertura das portas do Judiciário, entretanto não se pode ignorar os obstáculos atuais encontrados pela Justiça Brasileira que não consegue mais atender de forma satisfatória as demandas propostas.

O acesso ilimitado se tornou utópico, uma vez que aquele que desconhece suas limitações não consegue prover satisfatoriamente sua clientela. Ainda que no plano ideal o acesso irrestrito e ilimitado seja o almejado pela sociedade, as limitações financeiras, orçamentárias e estruturais existem e são relevantes.

O relatório do Justiça em Números de 2017, aponta que em 2016 ingressaram 29,4 milhões de novos processos, resultando em um acréscimo de 5,6\% em relação ao ano anterior. Assim, o número de processos pendentes continua aumentando. O crescimento acumulado no período foi de 31,2\%, ou seja, acréscimo de 18,9 milhões de processos de 2009 até 2016.

A estrutura em contrapartida não acompanha o crescimento significativo acima, ainda que se tenha registrado um marco histórico no ano de 2016, com 30,8 milhões de casos julgados, o esforço limitou-se ao quantitativo de processos novos. Em 2016, a carga de trabalho de um juiz de primeira instância foi de 7.192 processos. Esses números não são compatíveis com a eficiência e celeridades almejados nos trâmites processuais. 
A tragédia dos comuns vem elucidar que recursos limitados não podem produzir infinitamente. Dessa forma, partindo do pressuposto dos entraves existentes, é necessário que se repense o acesso à justiça para que ele seja efetivo e não apenas aparente.

A análise econômica da litigância é uma das ferramentas que auxilia na ponderação de estratégias para esse fim. A propositura de uma ação faz um balanço de custos e benefícios e enquanto os custos forem módicos o ajuizamento de ações, frívolas e habituais, por exemplo, continuará sendo atrativa, não se ignorando que questões econômicas estão presentes, inclusive, no Direito.

De igual forma, a racionalidade proposta na Teria dos Jogos é aspecto importante a ser considerado nesse tema. A condução de atitudes para o ajuizamento da resolução de um conflito, para sua composição ou até na forma procedimental escolhida no curso de uma ação é de acordo com uma estratégia escolhida pelas pessoas, que pesam todos os fatores que envolvem a demanda, tais como forma de pagamento dos honorários advocatícios, condições financeiras das partes, impacto em novas possíveis causas, entre outras.

Por conseguinte, a ideia de eficiência do Poder Judiciário deve ponderar todas as questões abordadas para que se possa definir a melhor estratégia a ser adotada pelo Poder Judiciário, uma vez que a eficiência constitucionalmente garantida se traduz na busca da utilização dos melhores meios possíveis para se avalizar a efetividade dos objetivos almejados da melhor forma possível.

A garantia de eficiência está relacionada à concretização da ação, utilizando racionalmente os recursos disponíveis, com presteza e empregando métodos e procedimentos adequados. Sendo assim, os novos anseios da sociedade almejam um Judiciário produtivo, célere, efetivo e eficiente são motivadores para as novas diretrizes do Conselho Nacional de Justiça que visam garantir a maximização desses valores.

O acesso à justiça além de garantir o ingresso das pessoas ao Judiciário, deve garantir que suas pretensões sejam analisadas com celeridade, observando todas as garantias constitucionais e com presteza. Sendo necessário, para tanto, mecanismos que realizem filtros para se evitar o colapso da estrutura.

A percepção de acesso à justiça atual necessita deixa de ser aparente para se tornar pragmático e autêntico, sem olvidar os obstáculos existentes.

\section{REFERÊNCIAS BIBLIOGRÁFICAS}


BAGGENSTOSS, Grazielly Alessandra. O Sistema de Precedente no CPC/2015: a calculabilidade das decisõs judiciais pátrias como segurança jurídica defendida pela análise econômica do direito. EALR, V. 8, no 2, p. 299-316, Jul-Dez, 2017. Brasília: Universidade Católica de Brasília, 2017.

BATISTA JÚNIOR, Onofre Alves Batista. Princípio Constitucional da Eficiência Administrativa. 2 ed. rev. e atual. Belo Horizonte: Fórum,2012.

BRASIL, Constituição da República Federativa do Brasil (1988). Emenda Constitucional n. 91, de .18 de fevereiro de 2016. Disponível em: < <http://www.planalto.gov.br/ccivil_03/constituicao/constituicao.htm>. Acesso em: 08 ago.2017.

BRASIL, Lei n. 9.784, de 29 de janeiro de 1999. Regula o Processo Administrativo no âmbito da Administração pública Federal. Disponível em: < http://wwwt.senado.gov.br/legbras/>. Acesso em 08 ago. 2017.

. Conselho Nacional de Justiça. Justiça em Números 2017. Disponível: < http://www.cnj.jus.br/files/conteudo/arquivo/2017/09/e5b5789fe59c137d43506b2e4ec4ed67. pdf $>$. Acesso em: 1 abr. 2018.

Conselho Nacional de Justiça. Manual de Mediação Judicial. 2015.

. Fundação Getúlio Vargas. Escola de Direito de São Paulo. Relatório ICJ Brasil 1º Semestre de
2017.Disponível em <http://direitosp.fgv.br/sites/direitosp.fgv.br /files/arquivos/relatorio_icj_1sem2017.pdf>
Acesso em 1 abr. 2018.

Supremo Tribunal Federal. Recurso Extraordinário com Agravo 729.870. Rio de Janeiro. Relator: Ministro Teori Zavaski. 08/10/2013.

CADEMARTORI, Luiz Henrique Urquhart. A discricionariedade administrativa e seu controle jurisdicional do Estado Constitucional e Democrático de Direito. Direito, teorias e sistemas - Estudos desenvolvidos no programa de pós-graduação em direito da UFSC- Luiz Henrique Urquhart Cademartori; Sergio Ricardo Ferreira Mota (Orgs.). Florianópolis: Insular, 2015.

FREITAS, Juarez. O Controle dos Atos Administrativos e os Princípios Fundamentais. 2 ed. rev e atual. São Paulo: Malheiros, 1999.

HILLBRECHT, Ronald. Economia Monetária. São Paulo: Atlas, 1999.

LAMY, Eduardo de Avelar; RODRIGUES, Horácio Wanderlei. Teoria Geral do Processo. 4 ed.rev. e atual. São Paulo: Atlas, 2016.

MACIEIRA, Maria Elisa; Maranhão, Mauriti. Como implementar a gestão em Unidades Judiciárias. São Paulo: FGV, 2010.

MACKAAY, Ejan; Análise Econômica do Direito.Tradução Rachel Sztajn. 2 ed.São Paulo: Atlas, 2015. 
MARCELLINO JÚNIOR, Julio Cesar. Análise Econômica do acesso á justiça: a tragèdia dos custos e a questão do acesso inautêntico. Rio de Janeiro: Lumen Juris, 2016.

MEZZAROBA, Orides; MONTEIRO, Cláudia Servilha. Manual de Metodologia da Pesquisa no Direito. 6 ed. São Paulo: Saraiva, 2014.

MORAES, Antonio Carlos Flores de. Legalidade, Eficiência e Controle da Administração Pública. Belo Horizone: Fórum, 2007.

NOHARA, Irene Patrícia. Direito Administrativo. 7 ed. rev.,atual, e ampl.-São Paulo: Atlas,2017.

Reforma Administrativa e Burocracia: impacto da eficiência na configuração do direito administrativo brasileiro. São Paulo: Atlas, 2012.

OST, François; A natureza à margem da Lei - A Ecologia à Prova do Direito. Lisboa: Piaget, 1995.

PATRÍCIO, Miguel C.T. Análise econômica da litigância. Coimbra: Almedina, 2005.

POSNER, Richard A. Problemas de filosofia do direito. Tradução de Jefferson Luiz Camargo. São Paulo: Martins Fontes, 2007.

ROSA, Alexandre Morais da. Guia do processo penal conforme a teoria dos jogos. 4 ed. rev. e ampl. Florianópolis: Empório do Direito, 2017.

TIMM, Luciano Benetti (org). (2012). Direito e economia no Brasil. São Paulo: Atlas.

TRAMONTINI. Daine Sandra. Gestão da Administração Pública: uma reflexão das relações entre os sujeitos e o Estado na garantia de direitos fundamentais. Direito, teorias e sistemas - Estudos desenvolvidos no programa de pós-graduação em direito da UFSC- Luiz Henrique Urquhart Cademartori; Sergio Ricardo Ferreira Mota (Orgs.). Florianópolis: Insular, 2015. 